\title{
Pre-service Teachers' Choice of Physical versus Electronic Instructional Materials
}

\author{
Yalin Kilic Turel \& Filiz Varol \\ Firat University, Turkey
}

\begin{abstract}
The main goal of the current study was to analyze early childhood and elementary pre-service teachers' choices of participant-designed materials and the reasons for their selection. To this end, 57 elementary and 39 early childhood teacher candidates were asked to design one physical material and one electronic material for instruction. Then, they were asked which type of material they would prefer if they were teaching and what their rationale was for this selection. The results revealed several dissimilarities between early childhood and elementary teacher candidates in terms of their choices and the reasons for their choices. In their rationale, elementary pre-service teachers more referred their limited technological knowledge while early childhood pre-service teachers took attention to the need for handson activities for their instruction. In general, participants raised critical questions related to teachers' technological knowledge, and teacher preparation programs as well as professional development programs regarding how to integrate such instructional technologies effectively into course activities to enhance learning.
\end{abstract}

Keywords: Instructional material; Instructional material design; Pre-service teachers; Early childhood education; Elementary education; Teacher education programs

\section{Introduction}

Use of instructional materials has become an outstanding research topic for instructors and researchers for decades. Historical voices in the field of education, including Montessori, Plato, Pestalozzi, Froebel, Owen, and Dewey, believed that young children should be taught through objects (Wolfe, 2002). As such, many educators and associations agree with these theorists and suggest that effective instruction in early education as well as in the elementary grades incorporates use of materials (Ball, 1992; Clements, 1994, 1999, 2002; Fuson \& Briars, 1990; Haugland, Bailey, \& Ruiz 2002; Marsh \& Cooke 1996; National Association of Education for Young Children-NAEYC, 1996, 2002; Thompson, 1992; Uttal, Scudder, \& Deloache, 1997; Varol \& Farran, 2006). Specifically, it is acknowledged that materials may enhance interaction between teacher and students as well as interaction among students, facilitate students' understanding, enrich retention, and maintain motivation (Jaakkola \& Nurmi, 2004; Mayer, 2003; Royer, 2002; Triona \& Klahr, 2003). Besides overall benefits of instructional materials, teachers' selections and their rationale in regard to the most appropriate material for their instructional context have potential to increase the effectiveness of their instruction and maximize benefits of instructional materials. 
Materials may have a myriad of types and characteristics. Although they are classified diversely including visual, oral, 2D, 3D, TV-based, computer-based etc., for this particular study materials are categorized into two main groups - electronic materials (EM) and physical materials (PM). Electronic materials are meant to be digital (virtual) materials that are designed by using a variety of computer software. These types of materials can be used via computers. On the other hand, physical materials for this study refer to concrete, non-digital, and 3D materials that learners can grab with their hands such as tangrams, blocks, and abacus.

The role of prevailing senses including hearing, seeing, and touching on young children's meaningful learning is an indisputable fact (Walker-Tileston, 2004). Materials can facilitate students' learning by addressing these senses during instruction. One commonly-held belief is that physical materials or sometimes called as concrete manipulatives that students can touch, hold, and feel are highly effective for young children's learning and, as a result, they have been frequently preferred by teachers (Clements, 1999). On the other hand, a growing trend advocates that teachers should more benefit from the possibilities of the electronic media and technology for their instruction (Gulbahar, 2008). Despite the numerous advantages of materials, their design and selection process may be demanding for teachers due to their limited technological knowledge and the difficulties (i.e. complexity, time consuming) of design (Joyes \& Chen, 2007). In order to facilitate children's learning, empower them to become active participants in their own learning, spark their curiosity, and ensure the desirable effects of the materials, teachers should benefit from their strategic knowledge.

\section{Strategic Knowledge}

Although instructional materials are considered as critical components of effective instruction, the success of their integration into instruction depends on teachers' strategic knowledge as defined by Goldstein (2008, p.450). Strategic knowledge comprises teachers' own content knowledge, pedagogical knowledge, and technological knowledge built up through experience, personal characteristics, and education they received. One situation in which strategic knowledge comes into play is the time when the teacher makes the selection of instructional materials to use when teaching. It helps teachers choose developmentally appropriate materials for their students. Furthermore, this material selection process entails teachers considering various aspects of their instruction including their instructional contexts, necessities and available resources (Goldstein, 2008; Klahr, Triona, \& Williams, 2007). In addition to these aspects, teachers' skills, knowledge, and perceptions about materials and their usage affect their material selections (Leinhardt, 1986; Struder \& Wetzel, 1999). Since teachers' competencies and perceptions begin to be shaped during their participation in teacher education program, preparing teacher candidates to be proficient in selecting, designing, developing, and utilizing appropriate materials for their students is a critical challenge for teacher education programs to overcome. Recently, with the need for preparing new generations of teachers, teacher education programs have been reformed in many countries in order to increase the quality of education. Turkey is a prime example of this situation.

In line with the reform actions in education all over the world, teacher education programs in Turkey have also been reformed by the Higher Education Council (HEC) (Grossman, Onkol, \& Sand, 2007). In Turkey, pre-service teachers are already provided with courses which emphasize 
concrete material design and usage. However, teacher candidates received limited information about electronic materials. One specific reform was to add a technology-related course to the program to train pre-service teachers to use instructional technologies effectively so as to enrich their instruction (Gulbahar, 2008). Thus, a core course entitled Instructional Technologies and Material Design (ITMD) was included in teacher education programs in 1998 by Higher Education Council (HEC, 2010). This course, ITMD, was used as the context of this study.

ITMD is a compulsory course that is offered to second-year pre-service teachers. The main goal of the course is to familiarize pre-service teachers with various forms of instructional technologies and digital and non-digital materials as well as the ways to select/design/integrate these materials into classrooms. Specifically, there are four main themes of the course: (a) possible ways to design, develop, evaluate, and improve instruction; (b) different media and technology formats; (c) media and technology integration into instruction to facilitate students' learning; and (d) possible ways to select, design, develop, and utilize technological materials.

The main goal of the current study is to achieve an in-depth understanding of the factors that preservice teachers take into consideration based on their strategic knowledge when they make decisions about their material selection in order to enhance their instruction. This study differs from other studies of teachers' strategic knowledge because it incorporates two different academic disciplines - early childhood education and elementary education. This study compares them with each other in terms of pre-service teachers' strategic knowledge playing role on their material selection. Thus, the results from the current study can be examined in two tiers: the determination of the general preferences of pre-service teachers and the examination of the early childhood and elementary pre-service teachers' preferences in terms of the similarities and differences. It is critical to learn pre-service teachers' thoughts about their reasons for material selection. Such information that comes from this study and similar studies may lead policy makers to re-form teacher education programs based on pre-service teachers' strategic knowledge during their education.

\section{Research Questions}

The following three research questions were specifically addressed in this study:

1. What types of instructional materials (electronic or physical) do pre-service teachers prefer to use?

2. What factors affect the pre-service teachers' instructional material selection?

3. What are the similarities and differences between early childhood and elementary preservice teachers in terms of the factors that affect their material selection?

\section{Methodology}

The current research is a part of a fifteen-week course entitled Instructional Technologies and Material Design (ITMD) during the 2009-2010 fall semester in a state university in eastern Turkey. 
One author of the present paper was served as instructor for the ITMD course. At the beginning of the course, 96 senior students, enrolled for the course in the Department of Early Childhood Education and in the Department of Elementary Education, were informed about the project and the procedures. The teacher candidates were asked for their consent to participate in such study and all agreed to participate. They were also informed that they could withdraw from the project at any time if they wished.

As a part of the course, participating pre-service teachers and the instructor met for three hours on a weekly basis throughout the semester. These meetings were designed to build a community of learners who could share skills and knowledge in technology. In addition, participant-chosen collaborative learning groups of two to four people were used which allowed the students to work together to design better materials. All pre-service teachers were given three days to create their own groups. To this end, the early childhood pre-service teachers created twenty groups and the elementary pre-service teachers created twenty three groups in order to complete the course requirements which include designing electronic and physical materials for their particular fields. Throughout the semester, in addition to the weekly meetings, students could request time with the instructor to receive further feedback or assistance. The qualitative research technique used in this study involved consistent comparison analysis (Glaser \& Strauss, 1967) in order to discern patterns and assertions about pre-service teachers' selection of instructional materials, including their reasons for material selection.

\section{Participants}

There were a total of 96 participants who were in their second year at a state university in eastern Turkey. Table 1 shows the programs and gender break-down of the participants.

Table 1. Sample Gender and Program Numbers

\begin{tabular}{lccc}
\hline & Male & Female & Total \\
\hline Early Childhood Education Program & 2 & 37 & 39 \\
Elementary Education Program & 27 & 30 & 57 \\
\hline
\end{tabular}

In both programs, there are certain courses that all pre-service teachers need to take. Two of them are technology-related courses that need to be taken in the first year. In those courses, teacher candidates learn how to use computers, Microsoft Office programs including Word, Excel, and Power Point, operating systems including Windows XP and Windows Vista, and web page design. All participant students passed those two courses. Another technology-related course that all pre-service teachers need to enroll in is the ITMD course, which is the context of this research study. The participants were taking this course at the time of the project. In this course, teacher candidates learn instructional technologies, instructional material types, teacher qualifications in designing/selecting materials, instructional material design, technology integration into instruction, and evaluation of instructional materials. As noted previously, teacher candidates met with the instructor once a week to discuss these topics. 


\section{Procedures}

The study, which was a part of the ITMD course, consisted of three stages. Each stage is explained in details below.

Stage-1 was initiated in the first week of the semester with a seminar to inform the pre-service teachers about the procedures, grouping, topic selection, and grading. During Stage-1, which lasted seven weeks, weekly meetings included two-hour lectures led by the instructor. During the lectures, the topics given above were covered. For the remaining hour, pre-service teachers were encouraged to discuss their experiences about their material design process, issues they were facing, and the ways to improve their materials. Each group of students was asked to design one physical material. The groups were free to choose any topic that was related to their major. At the end of the seven weeks, the materials were delivered to the instructor. The materials were assessed based on a rubric developed by the researchers and the participants. Mainly, the rubric consisted of items related to usability, content, and the educational value of the material. Examples of materials are puppets, a calendar, a geometry game about matching shapes, a story box, and so on. Pictures of two physical materials are given in Figure 1 and 2.

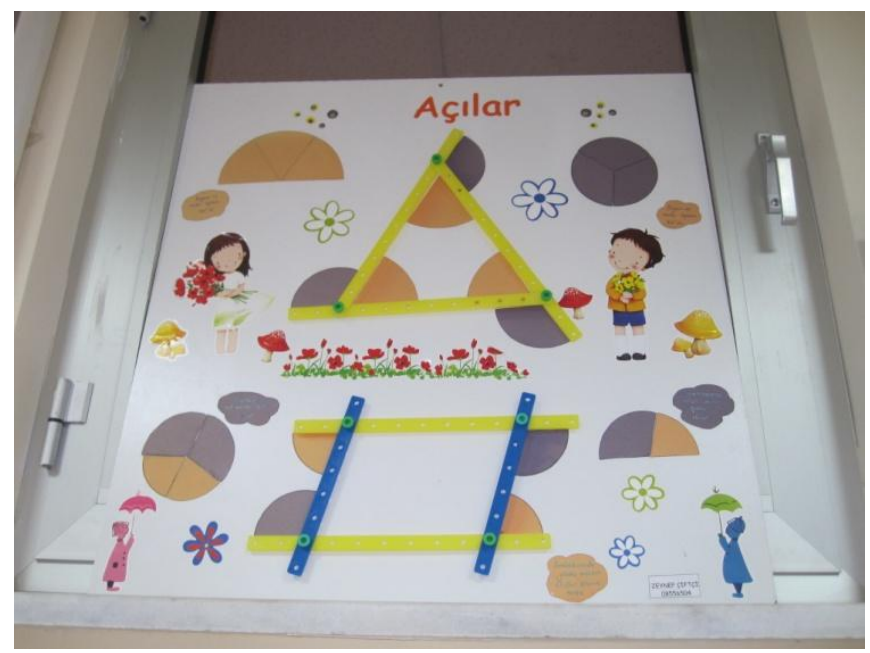

Figure 1. The Angles Board Prepared for Elementary School Students 


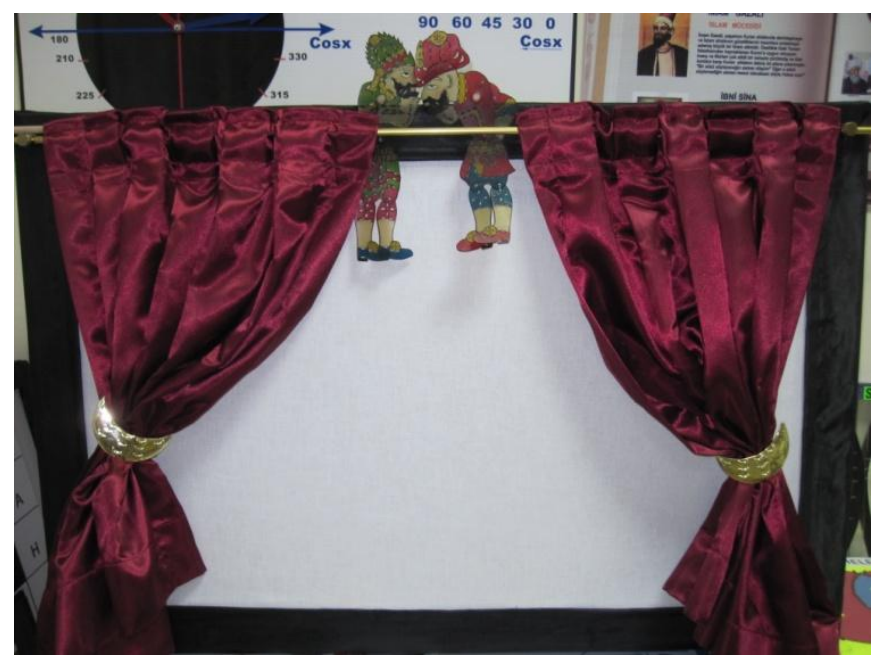

Figure 2. The Hacivat-Karagoz Puppets Stage Prepared for Young Children

After participants completed Stage-1, the second stage started. The same processes were performed as in Stage-1. Weekly meetings were devoted to lectures about instruction and technology as well as discussions about electronic material design and differences between physical and electronic materials. In order to elicit diverse perspectives, participants were asked to re-group to design their electronic material. They were given seven weeks for this purpose. The participants preferred to use Microsoft Power Point to design their electronic materials. At the end of the second stage, all e-materials were delivered to the instructor. The e-materials were evaluated and then assessed by the same rubric used for the physical materials. Due to the scope of the current manuscript, the rubrics designed to evaluate the physical and electronic materials are not discussed here. Captured pictures of two electronic materials are given in Figure 3 and 4.
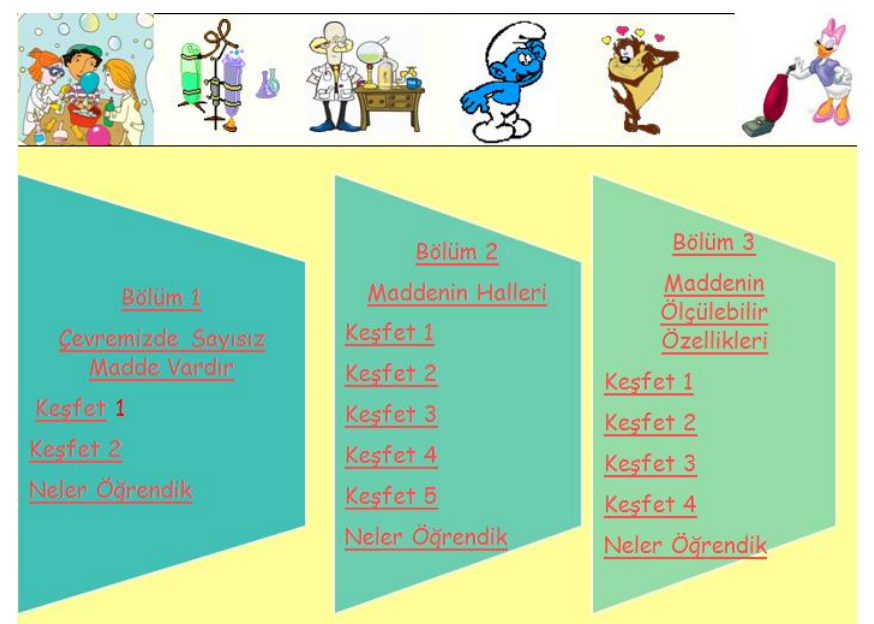

Figure 3. A Scene from an Electronic Material Prepared for Elementary School Students: "What is Matter?" 


\section{KURBAĞALAR}

- Yaşantılarının bir bölümünü suda bir bölümünü karada geçirir.

- Kışuykusuna yatar.
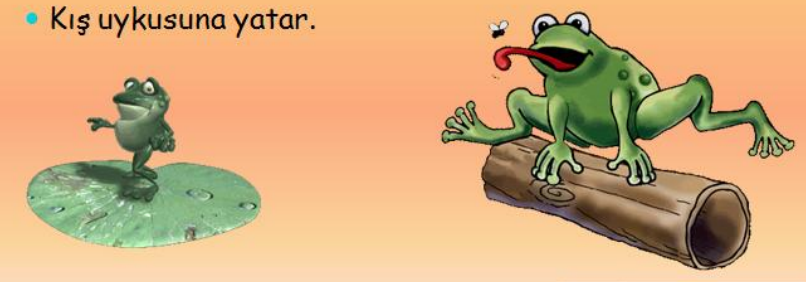

$\triangle$ 合|णि口

Figure 4. A Scene from an Electronic Material Prepared for Preschool Children: Animals

Regarding the topic selections, the total number of materials for physical (PM) and electronic materials (EM) are presented in Table 2.

Table 2. Topic Distributions for Materials

\begin{tabular}{lcccc}
\hline & \multicolumn{2}{c}{ Early Childhood Teacher Candidates } & \multicolumn{2}{c}{ Elementary Teacher Candidates } \\
& PM & EM & PM & EM \\
\hline Numbers & 6 & 5 & 7 & 7 \\
Geometry & 6 & 6 & 6 & 4 \\
Science & 1 & 4 & 5 & 9 \\
Literacy & 3 & 5 & 5 & 3 \\
Personal & 4 & - & - & - \\
Development & & & 23 & 23 \\
\multicolumn{1}{c}{ TOTAL } & 20 & 20 & & \\
\hline
\end{tabular}

In order to ensure that the materials were designed by the teacher candidates, artifacts about the design process were collected every week. Some examples of the artifacts are storyboard and drafts for electronic materials, captured pictures and/or videos of every step for physical materials.

Finally, Stage-3 was dedicated to collecting data about pre-service teachers' preference of instructional material and the reasons of their selection.

\section{Data Collection and Analysis}

In the last week of the semester, all participants met for the last weekly meeting which was devoted to obtaining participants' answers for the following questions: 
1. You have created a physical material and an electronic material. If you were a teacher, which material would you prefer to use to enrich your instruction?

2. What are your reasons for this selection?

It took from fifteen to thirty minutes for individuals to respond to those questions in written format. During the data collection, the researchers were present the entire time for assistance if needed. The data collected during Stage 3 were detailed enough to provide information about pre-service teachers' reasons for material selections.

All responses were transferred into electronic format. The data were analyzed using a computerassisted qualitative data analysis program (QSR NVivo 8). As a first step, pre-service teachers' preferences were identified. Based on the preliminary analysis, four themes were created for each major group: physical material, electronic material, cannot decide, and others. As per their preference, pre-service teachers were assigned to be in the physical material or electronic material group. If they stated that they cannot make a choice between them, then they were assigned to be in the "cannot decide" group. If a pre-service teacher talked about the advantages or disadvantages of materials - physical or electronic, - they were assigned to be in the others group. The pre-service teachers who were in the others group were dropped from the further analysis.

For the categorization of material selection, various dimensions of material design, development, utilization, and evaluation processes were examined through literature review (Jaakkola \& Nurmi, 2004; Lee, 2010; Mayer, 2003; Seels \& Richey, 1994; Triona \& Klahr, 2003; Yalin, 2004; Zacharia, 2007); and a draft theme schema was generated by the researchers. Main themes and sub-themes (codes) were formed by utilizing the draft schema as a general framework. All transcribed data related to teacher candidates' reasons for material selection were read carefully, and critical statements about participants' material selection and their rationale were identified based on the generated framework. Those statements were coded under free node option. Categories were then created, and the free nodes were associated with suitable categories. The free nodes under each category were reviewed by each researcher separately, and all agreed to the created associations.

In terms of pre-service teachers' reasons for their physical material selection, four themes were created. These themes were named as follows: design, environment and ergonomics, learning and instruction, and usefulness and effectiveness. In terms of participants' electronic material selections, five themes emerged: design, learning and instruction, technical advantages, use of technology, and usefulness and effectiveness.

The data were analyzed by two researchers separately. Inter-rater reliability was calculated by counting the matching categories of exact agreements among raters. The number of agreements was then divided by the sum of agreements and disagreements (Bijou, Peterson, \& Ault, 1968). An overall inter-rater reliability of $94 \%$ was obtained for the categories. For the disagreements, the agreed consensuses were used. The definitions of the categories and the codes are given in Appendix A. 


\section{Results}

\section{Instructional Material Preferences}

As seen in Figure 5, the results show that pre-service teachers voted for electronic materials more than physical materials. While almost half of the respondents (48\%) stated that they would prefer to use electronic materials in their teaching, only $38 \%$ of them chose physical materials. In addition, $4 \%$ of the respondents only talked about advantages and disadvantages of materials in general; thus, they were labeled as others.

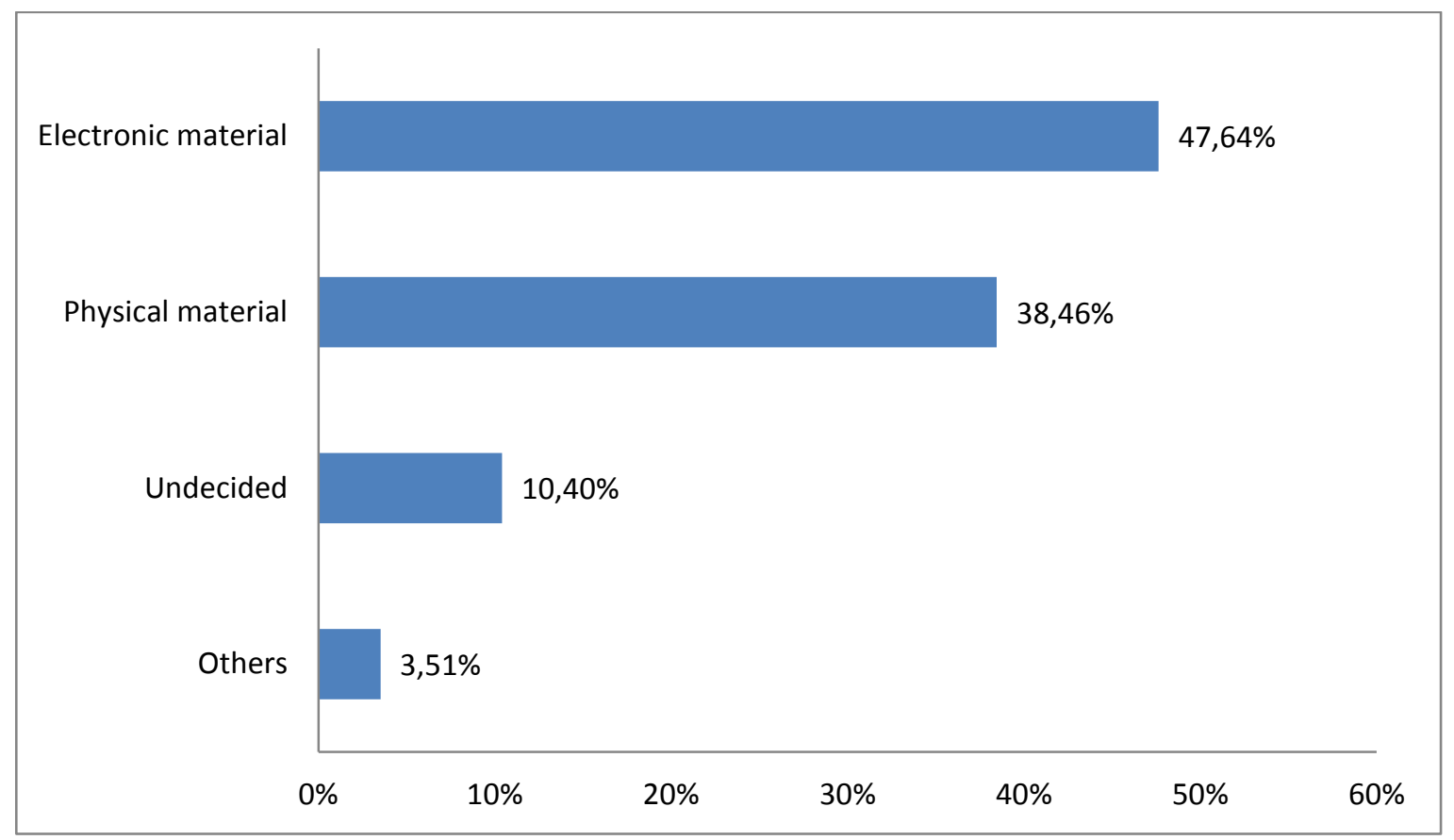

Figure 5. Pre-service Teachers' Instructional Material Preferences

Figure 6 shows the percentages of instructional material preferences of participants from two majors separately: early childhood education (ECpT) and elementary education (EpT).

As shown in the graph, while $49 \%$ of EpT and $46 \%$ of ECPT chose electronic materials, these numbers decreased to $33 \%$ and $44 \%$ for physical materials. On the other hand, about $10 \%$ of participants in each group mentioned that they could not choose between the materials and they would use both types of materials as they teach. In terms of physical material preferences, the comparison of EpTs with ECpTs shows an important distinction between both groups. ECpTs preferred physical materials more than EpTs. Possible reasons for this result are discussed in the following section. 


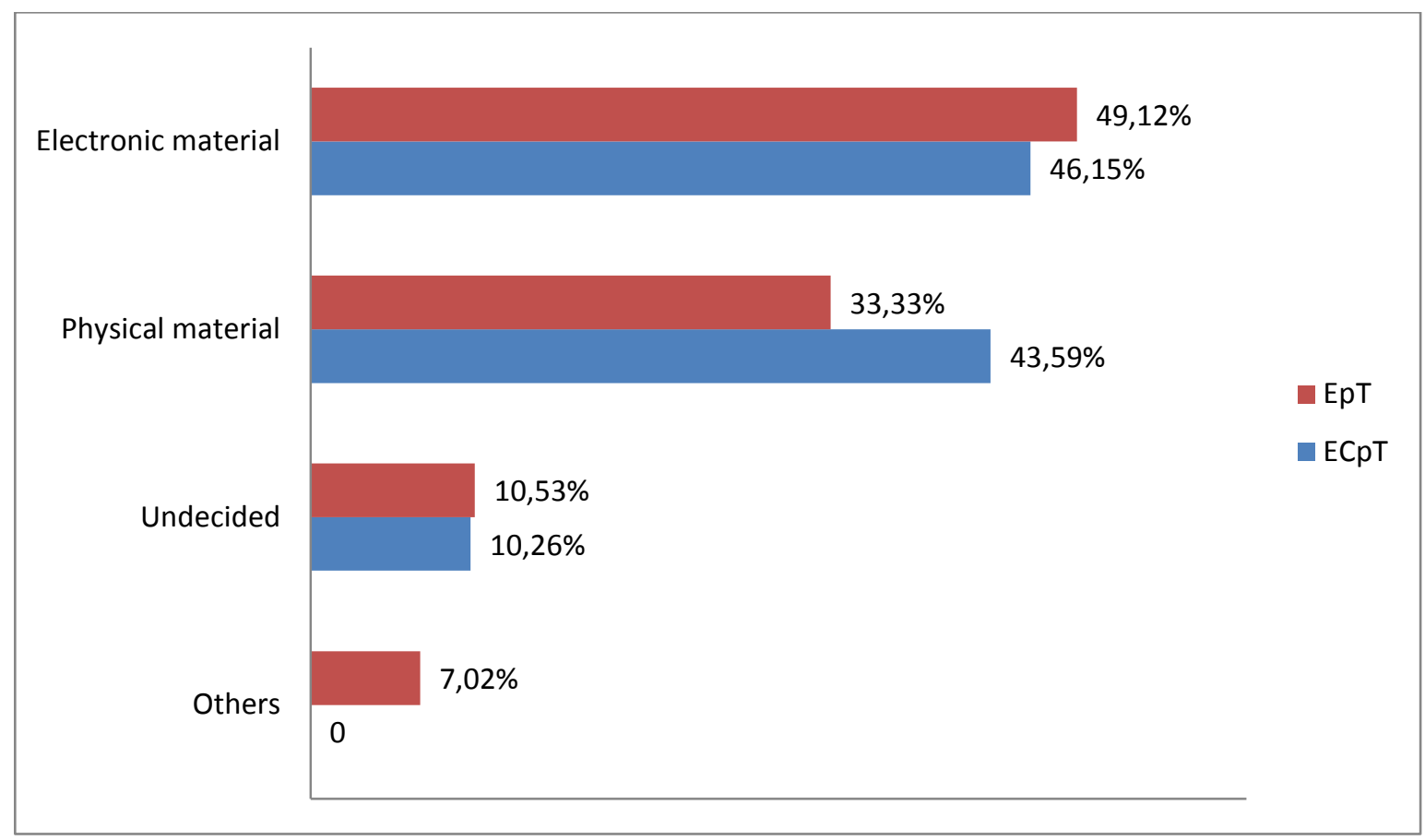

Figure 6. Pre-service Teachers' instructional Material Preferences by Their Majors

There were also four elementary pre-service teachers who only reported the advantages and disadvantages of both materials; thus, they were dropped from the further analyses.

\section{Pre-Service Teachers' Reasons for Material Selection}

This section discusses why both ECpTs and EpTs prefer to use physical or electronic materials. First, pre-service teachers' reasons for physical material selection are discussed. Then, their reasons for electronic material are examined.

\section{Pre-service teachers' reasons for physical material selection}

During the coding process, it emerged that there were four categories associated with participant teachers' selection of physical materials: design, environment and ergonomics, learning and instruction, and usefulness and effectiveness.

Table 3 provides the themes and the sub-themes and the number of pre-service teachers who mentioned them as a reason for their physical material selection.

According to the results, there are several distinctions between ECpTs and EpTs. In terms of design, one distinction is about design issues in EM that led EpTs to favor physical material. Six participants complained about not having personal computers so that they did not have enough opportunities to design a high-quality e-material. The general problem they highlighted was that 
Table 3. Categories of Pre-service Teachers' Reasons for Physical Material Selection

\begin{tabular}{|c|c|c|}
\hline \multirow[b]{2}{*}{ Categories } & \multicolumn{2}{|c|}{ Sources } \\
\hline & $\begin{array}{c}\text { Elementary } \\
\text { Pre-service Teachers }\end{array}$ & $\begin{array}{l}\text { Early Childhood } \\
\text { Pre-service Teachers }\end{array}$ \\
\hline \multicolumn{3}{|l|}{ Design } \\
\hline Design issues in e-material & 6 & 2 \\
\hline Effort & 3 & 1 \\
\hline Fun to design & 2 & 3 \\
\hline Limited knowledge in technology & 8 & 1 \\
\hline Satisfaction & - & 2 \\
\hline User-friendly & 2 & - \\
\hline Re-usability of the material & - & 2 \\
\hline Re-usability in other disciplines & 2 & 2 \\
\hline \multicolumn{3}{|l|}{ Environment and Ergonomics } \\
\hline Free of computers & 5 & 5 \\
\hline Health issues & 1 & 2 \\
\hline Interaction with others & 1 & 5 \\
\hline \multicolumn{3}{|l|}{ Learning and Instruction } \\
\hline Child development & 1 & 2 \\
\hline Creativity & 2 & - \\
\hline Educational & 4 & 4 \\
\hline Hands on activities & 9 & 11 \\
\hline Retention & 5 & 1 \\
\hline \multicolumn{3}{|l|}{ Usefulness and Effectiveness } \\
\hline Attractive & 2 & 1 \\
\hline Effective & 1 & 1 \\
\hline Fun to use & 5 & 5 \\
\hline Tactile & 3 & 7 \\
\hline Usefulness & 1 & 2 \\
\hline
\end{tabular}

the computer was used for material design by only one team member who was generally the owner of the computer. For example, one of those participants stated that

"One person did all the work for the e-material. But for the physical material, all of us worked on it. While one of us was cutting papers, another group member was painting, and another member was pasting."

Another distinction is related to pre-service teachers' knowledge of technology. While eight EpTs mentioned their limited knowledge of technology, this number decreased to one for ECpT. One EpT mentioned that her biggest limitation in designing e-material was about the software she used. According to her, she had not used the software previously so she was not able to use it effectively. She stated that she spent most of her time on learning the program, which resulted in less time in designing the e-material. Although both groups of pre-service teachers realized the importance of hands-on activities in order to support learners, early childhood pre-service 
teachers talked more about materials that were tactile. Note that hands-on activities refer to activities where children were actively engaged in manipulating materials - electronic or physical, which result in deeper cognitive gain. One ECpT specifically mentioned that

"I believe that hands-on materials are critical particularly for young children's development."

In addition, while five ECpTs pointed out the importance of interaction with teacher and peers in children's learning, only one EpT mentioned it. An ECpT stated that

"It is important for young children to play with their friends. They can interact more with the teacher and the peers while playing with hands on materials."

Another participant in the same group said that

"I vote for hands-on activities that support interaction between teacher and children, and among children."

Finally, the last distinction is associated with retention. In this paper, retention was used as a code whenever participants talked about opportunities that help learners remember information for a long period of time. There were five EpTs and only one ECpT who mentioned retention. An EpT said that

"With physical materials, children can see, hear, and touch while learning. In addition to those, trial and error has an effect on retaining knowledge. I mean physical materials help my children to have more permanent learning."

\section{Pre-Service Teachers' Reasons for Electronic Material Selection}

Five themes emerged from seventeen ECpTs' and twenty six EpTs' comments about their selection of electronic material to facilitate their instruction. These themes are design, learning and instruction, technical advantages, use of technology, and usefulness and effectiveness. Table 4 provides the themes and the sub-themes and the number of pre-service teachers who mentioned them as a reason for their electronic material selection. Among these themes, there are four major dissimilarities between ECpTs and EpTs.

Table 4. Pre-service Teachers' Reasons for Electronic Material Selection

\begin{tabular}{lcc}
\hline Categories & \multicolumn{2}{c}{ Sources } \\
& $\begin{array}{c}\text { Elementary } \\
\text { Pre-service Teachers }\end{array}$ & $\begin{array}{c}\text { Early Childhood } \\
\text { Pre-service Teachers }\end{array}$ \\
\hline Design & 6 & 1 \\
Availability for self and group work & 4 & 2 \\
Design issues in e-material & 2 & 1 \\
Effort & & \\
\hline
\end{tabular}




\begin{tabular}{lcc}
\hline Re-usability of the material & 6 & 4 \\
User-friendly & 1 & 2 \\
Visual & 8 & 4 \\
Cost-efficiency & 1 & - \\
Covering more learning objectives & 3 & 2 \\
Learning and Instruction & & 4 \\
Educational & 4 & 4 \\
Retention & 5 & 4 \\
Self-learning & 4 & \\
Technical Advantages & & 4 \\
Durability & 4 & 2 \\
Storage & 4 & 1 \\
Updatability & 3 & 5 \\
Use of technology & & \\
As a designer & 11 & 3 \\
As a user & 4 & 4 \\
Usefulness and Effectiveness & & - \\
Attractive & 1 & - \\
Effective & 4 & - \\
Time-efficiency & 6 & 9 \\
Space-efficiency & 2 & 3 \\
Usefulness & 4 & \\
Fun to use & 6 & 3 \\
Motivational & & \\
\hline
\end{tabular}

The first category is associated with electronic materials' availability for self and group work. While six EpTs stressed this aspect, only one ECpT mentioned it. An EpT said that

"The second material we designed, it can be used by an individual or it can be used in a classroom with all students."

The second dissimilarity is about use of technology. Being mentioned by only one ECpT, eleven EpTs addressed its importance for teachers to be able to use technology to design materials for their students. One teacher said that

"I believe that technology has significant effects on education and it will be the same in the future. So, if we are going to be future teachers, then, we have to benefit from technology effectively as much as we can."

Although the EpTs pointed out efficiency of electronic materials in terms of time and space, the ECPTs mentioned neither EMs space and time efficiency nor their usefulness. While six EpTs talked about time-efficiency of EMs, two EpTs mentioned its space-efficiency. One said that

"Students can continue learning whenever and wherever they want to if they use electronic materials." 


\section{Discussion}

The main goal of the current study was to determine early childhood and elementary pre-service teachers' choices of physical (PM) or electronic materials (EM) and the factors that affect their selections. To this end, 57 elementary (EpT) and 39 early childhood pre-service teachers (ECpT) were asked to design one physical material and one electronic material through group work. Then, they were asked which material they favored and what their rationale was for this selection.

A prominent finding of the study is about pre-service teachers' material selections. The total number of preferences per material reveals that participants chose EMs more than PMs. In other words, pre-service teachers perceived EMs to be more advantageous than PMs because of its reusability, time, space and cost efficiency, durability, and so on. This finding is parallel with the findings of Klahr et al. (2007), Zacharia (2007), and Arikan and Khezerlou (2010). However, once both groups of pre-service teachers are compared with each other, it seems that elementary preservice teachers preferred electronic materials more than early childhood pre-service teachers, while early childhood pre-service teachers preferred to use PMs more than elementary pre-service teachers. Furthermore, considering the undecided participants, it is notable that participants still value PMs as an essential resource for their instructions. Possible explanations for such results can be found in the reasons for pre-service teachers' material selection, which is discussed below.

According to the results, while making a selection, early childhood and elementary pre-service teachers elucidate certain advantages of the material they preferred. Examples of the advantages mentioned were material's - electronic or physical - usefulness and effectiveness, technical advantages, effects on learning, and so on. This finding is parallel with the findings of the 2007 study of Klahr and colleagues. When comparing the effects of physical and electronic materials on students' learning, Klahr et al. (2007) emphasized that both kinds of materials help children become active learners. In addition, they contended that EMs have advantages including reusability, updatability, manageability, and saving from time and space, while PMs provide opportunities for learners to use their tactile senses.

Although the participants in this study referred to these advantages, the emphasis on each advantage differs based on participants' major as discussed previously. As expected, both elementary and early childhood pre-service teachers took into account the developmental stages of their target age group, possible physical conditions of their future classrooms, and their course contents as making their selections. For instance, elementary pre-service teachers stressed EMs' usefulness, time and space efficiency, and availability for self and group work more than early childhood pre-service teachers. This might be due to the target group that elementary teachers teach and the topics they would need to cover in various discipline areas. On the other hand, early childhood pre-service teachers stressed providing tactile materials to young children more than elementary pre-service teachers. They also put strong emphasis on tactile materials by talking about the importance of providing hands-on activities for young children as a reason for their physical material selection. These results support the findings of Heddens (1986 as cited in Lee 2010), Klahr and colleagues (2007), Lee (2010), Manches and colleagues (2010), and Triona and Klahr (2003). For instance, as Lee (2010) points out, "children are naturally aware of attributes of geometric shapes when they manipulate and play with concrete materials. Providing time for 
children to explore three-dimensional materials in space would help them build foundations for later geometry learning" (p.36). In short, emphasis on hands-on activities and use of manipulative materials instead of abstract or semi-abstract materials for pre-school students' effective learning may be due to children's initial stages of their cognitive development processes.

However, although they have critical effects on young children's learning, hands-on activities do not necessarily have to be conducted with physical materials. For example, new generation electronic materials which contain elements such as simulation, interactivity, and virtual reality may offer different benefits even for young children in school settings. Thus, future research should examine especially how to enhance early childhood pre-service teachers' experiences regarding hands-on activities with various types of materials and their perceptions towards such implementations.

In addition, the results raised critical aspects related to pre-service teachers' exposure to technology - being able to use technology to design electronic materials and being able to integrate technology into their instruction. Many studies advocate the importance of effective ICT integration into classroom settings and use of the potential of these technologies for teachers (Hammonds, Reynolds, \& Ingram, 2011). Moreover, as Prensky (2001, p.1) suggested, "Today's students are no longer the people our educational system was designed to teach." Although elementary pre-service teachers verbalized their limited knowledge in technology as a reason to choose physical material and how critical it is for prospective teachers to be able to use technology, early childhood pre-service teachers did not mention these two aspects, which might be due to their belief that hands-on activities can only involve tactile materials. Similar results were presented by Ulas and Ozan (2010) and Gulbahar (2008). Thus, these results may suggest critical changes in teacher education programs by increasing the number of technology-related courses and enhancing their content. Beyond this, teacher educators should be a model for preservice teachers by showing their enthusiasm for using instructional materials in teaching. As Bai and Ertmer (2008) and Strudler and Wetzel (1999) suggested, in order to encourage pre-service teachers to benefit from technology, it may be critical to examine pre-service teacher educators' knowledge and skills in and attitudes towards technology. It might be necessary to provide professional development opportunities with emphasis on technology for faculty members who are a part of teacher education programs- how to use technology as a tool to enhance learning and as a part of an assessment.

\section{Conclusion and Suggestions}

The current study examined early childhood and elementary pre-service teachers' choices of materials and their reasons for their material selection. The results raise general implications for teacher preparation programs. Determining the needs for the change of teacher preparation programs in regard to use of ICT, teacher's unwillingness to use the EM, as a core aspect of the ICT integration, should be well-analyzed. For example, the major implication of this study is that preservice teachers have limited knowledge of technology, especially in designing electronic materials in spite of their strong belief about the important role of technology on young students' learning. 
The results seem to indicate that more and detailed mandatory computer instruction is necessary for pre-service teachers so that they can advance their skills and practices in technology. Such courses would provide opportunities for pre-service teachers to enhance their skills in using internet effectively to find/benefit from reliable resources and using various programs to create, edit, view, and print documents, which enrich their instruction. Another suggestion could be about teacher educators and their use of technology level as they teach. Teacher educators need to be models for pre-service teachers by integrating technology into their instruction. While pre-service teachers advance their theoretical knowledge in technology by taking mandatory computer instruction, they can see different applications of technology by observing their professors using technology. Future research is needed to examine the association between the level of teacher educators' instructional material use and pre-service teachers' attitudes towards instructional materials.

Another implication is related to hands-on materials. The results show that some pre-service teachers do not consider electronic materials as hands-on material. However, although they have critical effects on young children's learning, hands-on activities do not necessarily have to be conducted with physical materials. For example, new generation electronic materials which contain elements such as simulation, interactivity, and virtual reality may offer different benefits even for young children in school settings. Thus, future research should examine especially how to enhance early childhood pre-service teachers' experiences regarding hands-on activities with various types of materials and their perceptions towards such implementations.

The study may be limited by focusing only on pre-service teachers whose specializations were on early childhood education and elementary education and who enrolled in a technology-related class. Thus, because of these limitations the results may not be generalized to other pre-service teachers from different academic disciplines and at other teacher preparation programs. However, because of the uniqueness of the current study in examining similarities and differences of early childhood and elementary pre-service teachers, the benefits of this study outweigh its limitations. The results of this study yield valuable data on the factors that affect pre-service teachers' material selection and, in line with this, on the possible reform actions for teacher preparation programs. Further research is needed in this area with other pre-service teachers majoring in related areas in order to determine whether the results of the current study can be generalized to broader populations.

\section{References}

Bai, H. \& Ertmer, P. (2008) Teacher educators' beliefs and technology uses as predictors of preservice teachers' beliefs and technology attitudes. Journal of Technology and Teacher Education, 16(1), 93-112.

Bijou, S.W., Peterson, R.F., \& Ault, M.H. (1968). A method to integrate descriptive and experimental field studies at the level of data and empirical concepts. Journal of Applied Behavior Analysis, 1(2), 175-191. 
Glaser, B. \& Strauss, A. (1967). The discovery of grounded theory: Strategies in qualitative research. London: Wiedenfeld and Nicholson.

Gulbahar, Y. (2008) Improving the technology integration skills of prospective teachers through practice: A case study. Turkish Online Journal of Educational Technology, 7(4), 71-81.

Hammond, M., Reynolds, L., \& Ingram, J. (2011), How and why do student teachers use ICT? Journal of Computer Assisted Learning, 27, 191-203.

HEC-Higher Education Council. (2010). Guide for pre-service teachers. Retrieved 20 August 2010 from http://www.yok.gov.tr/index.php?option=com_docman\&task=doc_download\&gid=70

International Society for Technology in Education. (2000). National educational technology standards for students: Connecting curriculum and technology. Eugene, OR: Author.

Jaakkola, T. \& Nurmi, S. (2004). Academic impact of learning objects: The case of electric circuits. Paper presented at the BERA (British Educational Research Association) 2004 Conference. Manchester, UK, 16-18.9.2004 (ERIC database document ED489898).

Joyes, G. \& Chen, Z (2007). Researching a participatory design for learning process in an intercultural context. International Journal of Education and Development using Information and Communication Technology (IJEDICT), 3(3), 78-88.

Klahr, D., Triona, L.M., \& Williams, C. (2007). Hands on what? The relative effectiveness of physical versus virtual materials in an engineering design project by middle school children. Journal of Research in Science Teaching, 44, 183-203.

Lee, J. (2010). Exploring kindergarten teachers' pedagogical content knowledge of mathematics. International Journal of Early Childhood, 42(1), 27-41.

Leinhardt, G. (1986). Expertise in mathematics teaching. Educational Leadership, 43(7), 28-33.

Maches, A., O'Malley, C., \& Benford, S. (2010). The role of physical representations in solving number problems: A comparison of young children's use of physical and virtual materials. Computers \& Education, 54(3), 622-640.

Mayer, R. E. (2003). The promise of multimedia learning: Using the same instructional design methods across different media. Learning and Instruction,13, 125-139.

Niederhauser, D.S. \& Stoddart, T. (2001). Teachers' instructional perspectives and use of educational software. Teaching and Teacher Education, 17, 15-31.

Niess, M.L. (2005). Preparing teachers to teach science and mathematics with technology: Developing a technology pedagogical content knowledge. Teaching and Teacher Education, 21, 509-523.

Prenksy, M. (2001). Digital Natives, Digital Immigrants. On the Horizon, 9(5). Available online at: http://www.marcprensky.com/writing/Prensky\%20-\%20Digital\%20Natives,\%20Digital\% 20Immigrants\%20-\%20Part1.pdf

Royer, R. (2002). Supporting technology integration through action research. The Clearing House, 75, 233-237.

Seels, B. B. \& Richey, R. C. (1994). Instructional technology: The definition and domains of the field. Washington, DC: Associations for Educational Communications and Technology. 
Strudler, N. \& Wetzel, K . (1999). Lessons from exemplary colleges of education: Factors affecting technology integration in preservice programs. Educational Technology Research \& Development, 47(4), 63-81.

Triona, L.M. \& Klahr, D. (2003). Point and click or grab and heft: Comparing the influence of physical and virtual instructional materials on elementary school students' ability to design experiments. Cognition \& Instruction, 21, 149-173.

Ulas, A. H. \& Ozan, C. (2010). The qualification level of primary school teachers' use of educational technology. Journal of Graduate School of Social Sciences, 14(1), 63-84.

Varol, F. \& Farran, D. C. (2006). Early mathematical growth: How to support young children's mathematical development. Early Childhood Education Journal, 33(6), 381-387.

Walker-Tileston D. (2004). What every teacher should know about media and technology. Thousand Oaks, CA: Corwin.

Yalin, H. I. (2004) Ogretim teknolojileri ve materyal gelistirme $\left(12^{\text {th }}\right.$ ed.). Ankara: Nobel.

Zacharia, Z.C. (2007). Comparing and combining real and virtual experimentation: An effort to enhance students' conceptual understanding of electric circuits. Journal of Computer Assisted Learning, 23, 120-132.

\section{APPENDIX A}

Coding schema to categorize pre-service teachers' comments about their selection of material

\begin{tabular}{|c|c|}
\hline Categories & Definition \\
\hline \multicolumn{2}{|l|}{ Design } \\
\hline Design issues in e-material & $\begin{array}{l}\text { Refers to the issues students faced as they were designing e-material } \\
\text { that led them to choose physical material }\end{array}$ \\
\hline Effort & Refers to the effort students put in designing a material \\
\hline Fun to design & Refers to the fun a student had as he/she designed a material \\
\hline $\begin{array}{l}\text { Limited knowledge in } \\
\text { technology }\end{array}$ & Refers to students' limited knowledge in technology \\
\hline Re-usability of the material & Refers to the materials usability again and again \\
\hline Satisfaction & Refers to students' satisfaction with the its design \\
\hline User-friendly & Refers to materials' feature of being user-friendly \\
\hline $\begin{array}{l}\text { Availability for self and } \\
\text { group work }\end{array}$ & Refers to comments about individual or group use of the material \\
\hline $\begin{array}{l}\text { Covering more learning } \\
\text { objectives }\end{array}$ & $\begin{array}{l}\text { Refers to a wide range of course content that can be presented through a } \\
\text { material. }\end{array}$ \\
\hline Cost-efficient & Refers to comments about cost efficiency of materials \\
\hline Visual & Refers to comments about the aesthetic appeal of materials \\
\hline \multicolumn{2}{|l|}{ Environment and Ergonomics } \\
\hline Free of computers & $\begin{array}{l}\text { Refers to not having access to at least one computer in order to use an e- } \\
\text { material }\end{array}$ \\
\hline Health issues & Refers to the health issues that being in front of a computer may cause \\
\hline Interaction with others & Refers to an advantage of a material as using it with a teacher/peers \\
\hline
\end{tabular}


Learning and Instruction

Child development

Creativity

Educational

Hands on activities

\begin{tabular}{|c|c|}
\hline \multirow{2}{*}{\multicolumn{2}{|c|}{ Self-learning }} \\
\hline & \\
\hline Retention & $\begin{array}{l}\text { Refers to the advantage of a material that helps students remember } \\
\text { information }\end{array}$ \\
\hline \multicolumn{2}{|c|}{ Technical Advantages } \\
\hline Durability & Refers to the longevity of a material \\
\hline Storage & Refers to facilities for storing a material \\
\hline Updatability & Refers to material modification or inclusion of new features to it \\
\hline \multicolumn{2}{|c|}{ Usefulness and Effectiveness } \\
\hline Attractive & Students' comments about attractiveness of a material \\
\hline Effective & Students' comments about effectiveness of a material \\
\hline Fun to use & $\begin{array}{l}\text { Students' comments about fun a learner may have as he/she uses a } \\
\text { material }\end{array}$ \\
\hline Tactile & Students' comments about tactility/tangibility of a material \\
\hline Usefulness & Students' comments about usefulness of a material \\
\hline Time-efficient & $\begin{array}{l}\text { Students' comments about spending time for development and } \\
\text { utilization of a material }\end{array}$ \\
\hline Space-efficient & Students' comments about space efficiency of a material \\
\hline Motivational & Students' comments about motivational effects of a material on students \\
\hline
\end{tabular}

Correspondence: Yalin Kilic Turel, Assistant Professor, Department of Computer Education and Instructional Technologies, Faculty of Education, Firat University, Elazig, Turkey 